\title{
Bases e fundamentos legais para a discussão de gênero e sexualidade em sala de aula
}

\section{Bases and legal foundations for the discussion of gender and sexuality in the classroom}

https://doi.org/10.34112/2317-0972a2016v34n68p93-106

Alex BARreiro ${ }^{1}$

Fernando Henrique Martins ${ }^{2}$

RESUMO: Este artigo é resultado de uma série de levantamentos realizados em diversas documentações, como: Leis de Diretrizes e Bases da Educação, resoluções emitidas pelo Conselho Nacional de Educação; legislações da área educacional brasileira e também artigos da Constituição Federal, concedendo bases e fundamentos legais para que as discussões de gênero e sexualidade sejam desenvolvidas por professoras/es através de atividades e propostas pedagógicas diferenciadas. Busca-se por meio da crítica cultural e dos dispositivos legislativos produzidos ao longo das últimas décadas no país, questionar as recentes decisões tomadas pelas câmaras municipais brasileiras, retirando e, em alguns casos, proibindo que as discussões de gênero e sexualidade sejam tratadas no âmbito institucional da educação pública. Para isso, recorreremos aos estudos e teorias pós-estruturalistas, enfatizando que a inserção das discussões de gênero e sexualidades nas escolas podem ser compreendidas como importantes medidas educativas para a desconstrução da colonialidade do ser e do saber.

Palavras-chave: Gênero; sexualidade; educação; pós-colonialismo.

1. Universidade Estadual de Campinas, Campinas, SP, Brasil.

2. Faculdades Integradas Maria Imaculada, Mogi Guaçu, SP, Brasil. 
ABSTRACT: This article is the result of a series of studies carried out in several documents, which include the Brazilian Guidelines and Standards of Education, the resolutions issued by the National Board of Education; the Brazilian Legislation on Education and also the Federal Constitution, granting bases and legal foundations for discussions of gender and sexuality to be developed by teachers through different pedagogical activities and proposals. Based on cultural criticism and legislation produced in the last decades in the country, our objective is to question recent decisions taken by the Brazilian city councils, withdrawing and, in some cases, prohibiting discussions of gender and sexuality from taking place in the scope of public education. Resorting to poststructuralist theories and studies, we highlight the fact that the insertion of gender and sexuality discussions in schools can be understood as important educational measures for the deconstruction of the coloniality of the being and of the knowledge. KeYWoRDS: Gender; sexuality; education; postcolonialism.

O autor Walter Mignolo, em (Des)Colonialidad del ser y del saber (vídeos indígenas y los limites coloniales de la ezquierda) en Bolivia, destaca que a lógica da colonialidade opera em três diferentes níveis: a colonialidade do poder (referente aos processos econômicos e políticos); a colonialidade do saber (condizente com as questões de natureza epistêmica, filosófica, científica e com as relações de línguas e conhecimento); e a colonialidade do ser (ou seja, dos aspectos relacionados à subjetividade, ao controle da sexualidade e aos papéis atribuídos aos gêneros).

Para o autor:

En la medida en que los imperios occidentales, capitalistas y cristianos (protestantes y católicos) formados en los últimos cinco siglos de historia del Atlantico proyectada sobre el resto del globo, son co-extensivos con la idea de modernidad, la colonialidad aparece como el lado más escuro e invisible de ella. La colonialid, en otras palabras, es constitutiva de la modernidade. Y en la medida en que la colonialidad del poder, del saber y del ser se asienta sobre el racismo y el patriarcalismo, los movimientos sociales identitarios son hoy las respuestas contundentes a la colonialidad del saber e del ser y, en consecuencia, de la colonialidad del poder (MIGNOLO, 2006, p. 16).

Assim, as teorias denominadas decolonialistas emergem como um novo campo teórico e, sobretudo, epistemológico do conhecimento, analisando o impacto provocado pelo processo de colonização na América Latina e no Caribe, ressaltando as três instâncias estruturais que constituíram e ainda mantêm sustentável a 
hegemonia dos saberes e dos conhecimentos eurocêntricos, sendo eles: a colonialidade do poder, do saber e do ser, os quais, inclusive, gerenciam as relações culturais, sociais e pessoais, interferindo não apenas nas dinâmicas econômicas e políticas, como também no processo de subjetivação (LANDER, 2005).

A pedagogia e consequentemente a educação formal aparecem como lócus privilegiado para a manutenção dos interesses ideológicos de Estado e das instituições que se agregam aos aparelhos estatais, como nos lembra Cambi (1999), as quais secularmente, de acordo com Foucault, regularam e disciplinaram os corpos, colocando-os a serviço das políticas e dos métodos das mais distintas instituições: "esses métodos que permitem o controle minucioso das operações do corpo, que realizam a sujeição constante de suas forças e lhes impõem uma relação de docilidade-utilidade, são o que podemos chamar de disciplinas" (FOUCAULT, 1987, p. 118); portanto, o corpo, para Foucault $(1987$, p. 118), "é um corpo que pode ser submetido, que pode ser utilizado, que pode ser transformado e aperfeiçoado".

Em Género y descolonialidad, Mignolo (2014) afirma que nos devemos desprender das ficções naturalizadas e empreendidas pelas matrizes coloniais do poder exercido sobre a produção do conhecimento e da subjetividade, pois a construção do conceito de modernidade produziu feridas coloniais, patriarcais, como normas e hierarquias que regularam o gênero e a sexualidade humana, e também as questões étnicas, promovendo o entretenimento banal que narcotizou o pensamento.

As normas e hierarquias que regularam o gênero e a sexualidade humana, naturalizando determinadas condutas e comportamentos mencionados pelo autor, nos fazem recordar o conceito de performatividade desenvolvido pela filósofa Judith Butler, que questiona exatamente a noção essencialista substanciada na anatomia humana, a qual concebe o gênero como um atributo interligado ao sexo biológico. Para Butler:

Nesse sentido, o gênero não é um substantivo, mas tampouco é um conjunto de atributos flutuantes, pois vimos que seu efeito substantivo é performativamente produzido e imposto pelas práticas reguladoras da coerência do gênero. Consequentemente, o gênero é sempre um feito, ainda que não seja obra de um sujeito tido como preexistente à obra. No desafio de repensar as categorias do gênero fora da metafísica da substância, é mister considerar a relevância da afirmação de Nietzsche, em A genealogia da moral, de que "não há 'ser' por trás do fazer, do realizar e do tornar-se; o 'fazedor' é uma mera ficção acrescentada à obra - a obra é tudo” (BUTLER, 2008, p. 48, grifo do autor). 
A noção de natureza surge como uma política estratégica, sendo possível por meio dela legitimar uma série de desigualdades e direitos, acondicionando a mulher e o gênero feminino constituído socioculturalmente ao ambiente privado. Dessa forma, como ressaltaram Miguel e Biroli (2014, p. 33), "é impossível descolar a esfera política da vida social, a vida pública da vida privada, quando se tem como objetivo a construção de uma sociedade democrática". Público e privado encontram-se constantemente em movimento simbiótico.

Nessa dinâmica segregacionista fundamentando as diferenças de gênero pela distinção de natureza anatômica e, muitas vezes, recorrendo às explicações de caráter religioso - teológico - funciona o aparelho de manutenção das desigualdades sociais, desvalorizando e subalternizando as profissões e as atividades ocupadas por mulheres e pelo gênero feminino majoritariamente e permitindo aos homens usufruir de melhores salários e oportunidades nas áreas em que possuem seus cargos.

A busca pela equidade de gênero exige não somente políticas afirmativas, mas também um intenso e progressivo trabalho educacional, seja essa educação no âmbito formal ou informal. Por essas e outras razões, o Brasil vem há algumas décadas debatendo as formações docentes e discentes, propondo novos conteúdos curriculares e pedagógicos que contemplem essas questões e atuem como propulsores no combate às discriminações e às desigualdades de gênero.

\section{GÊnero e Sexualidade NAS ESCOLAS: BASES E FUndamentos LEgais}

Recentemente, em todo o Brasil, a palavra "gênero" conquistou espaço e visibilidade em diferentes setores sociais, dentre os quais podemos destacar o campo político, o religioso e, sobretudo, o educacional. Adultos e adultas, jovens e adolescentes que antes sequer haviam escutado a palavra "gênero" passaram a pesquisar sobre o assunto e sobre as problemáticas e polêmicas em torno dessa categoria sociológica, permitindo que o tema circulasse por lugares e instituições que até então despertavam pouco interesse ou eram pouco acessíveis.

As discussões emergiram do embate político federal e posteriormente estadual e municipal sobre a necessidade de se trabalhar e discutir com as crianças - desde a pré-escola - as maneiras arbitrárias e impositivas de construção das masculinidades e feminilidades, as quais configuram um território prescritivo e pouco livre para as manifestações de meninos e meninas que queiram experienciar atividades e fazeres outros, não socialmente inscritos pelas convenções socioculturais hegemônicas e 
colonizadas para um determinado sexo biológico. Dessa forma, a defesa da inserção dos estudos de gênero na educação básica brasileira visa não meramente propiciar a livre manifestação de gênero, mas também desenvolver a longo prazo um trabalho de construção da equidade de direitos, partindo das diferenças das identidades e/ ou dos papéis de gênero. Assim, os valores hierárquicos historicamente herdados do patriarcado $\mathrm{e}^{3}$ que operam para a permanência das desigualdades entre homens e mulheres e entre as atividades masculinas e femininas seriam, pouco a pouco, destituídos do espaço da educação institucional. E promoveriam, por meio de diferentes dispositivos ${ }^{4}$ pedagógicos, formas de compreensão que permitam abranger as profissões, as funções sociais, o direito ao corpo e o exercício pleno da cidadania como parte do processo da subjetividade, e não meramente como marcadores sociais das diferenças determinantes nas escolhas e nas posições (sociais, políticas e econômicas) de homens e mulheres no decorrer de suas vidas.

Contudo, mobilizados pelos discursos maniqueístas orquestrados pelos setores conservadores, compostos por segmentos religiosos de diferentes matrizes cristãs, como católicos, protestantes, adventistas entre outros, os debates acerca das discussões de gênero nas escolas passaram a adquirir uma dimensão escatológica, que chegou, inclusive, a ser tratada como uma medida que destruiria a "família tradicional" brasileira. Algumas lideranças políticas e religiosas argumentavam que as práticas de gênero confundiriam a orientação sexual das crianças e dos adolescentes, conduzindo-os à homossexualidade, à bissexualidade e à transexualidade e, em alguns casos, poderiam ser relacionadas com a permissão da prática da pedofilia.

Os debates nas câmaras municipais ocorreram de forma acalorada, movimentando grupos políticos favoráveis e contrários às discussões na educação básica, e em

3. Trata-se de um cargo ou jurisdição de um patriarca. Termo que abrange diferentes significados atualmente, podendo, ser entendido como o conjunto de leis (escritas ou não escritas) que privilegiam e priorizam os homens nas dimensões sociais, culturais, políticas e que refletem na perspectiva econômica.

4. A noção de dispositivo em Michel Foucault é vasta e esparsa, englobando diferentes instituições, arquiteturas e produção de saberes dispositivos. Contudo, pode também ser referida como: “1) a rede de relações que podem ser estabelecidas entre elementos heterogêneos: discursos, instituições, arquitetura, regramentos, leis, medidas administrativas, enunciados científicos, proposições filosóficas, morais, filantrópicas, o dito e o não dito. 2) O dispositivo que estabelece a natureza do nexo que pode existir entre esses elementos heterogêneos. Por exemplo, o discurso pode aparecer como programa de uma instituição, como um elemento que pode justificar ou ocultar uma prática, ou funcionar como uma interpretação a posteriori dessa prática, oferecer-lhe um campo novo de racionalidade. 3) Trata-se de uma formação que, em um momento dado, teve por função responder a uma urgência. $O$ dispositivo tem assim uma função estratégica” (CASTRO, 2009, p. 123).

5. Parte dos estudos filosóficos e teológicos que tratam dos últimos eventos na história do mundo ou da espécie humana. A escatologia está associada às profecias messiânicas. 
muitas cidades chegaram a ser adiadas as sessões dos órgãos legislativos, em decorrência da indignação de parcela da população que considerava a exclusão dos debates de gênero um retrocesso para a construção do respeito às diferenças e também aos direitos das mulheres e da população LGBTT. Exemplos podem ser destacados, como nos casos de grandes cidades brasileiras, como Maceió ${ }^{6}$, Campinas, ${ }^{7}$ entre outras.

Por fim, prevaleceu majoritariamente, em muitos municípios, a decisão de retirar a palavra "gênero" dos planos municipais de educação, o que não significa que a professora ou o professor não possa ou esteja proibido de trabalhar essas questões em sala de aula. Pelo contrário, existe um arcabouço legal que autoriza, fundamenta e entende o desenvolvimento de atividades e projetos que abordem as relações de gênero em sala de aula como medidas relevantes e de extrema importância para o desenvolvimento do exercício da cidadania e da dignidade humana. Vejamos quais são alguns deles.

Consta nas Leis de Diretrizes e Bases da Educação Básica brasileira ${ }^{8}$ que:

Art. $1^{\circ}$ A educação abrange os processos formativos que se desenvolvem na vida familiar, na convivência humana, no trabalho, nas instituições de ensino e pesquisa, nos movimentos sociais e organizações da sociedade civil e nas manifestações culturais. Art. $2^{\circ} \mathrm{A}$ educação escolar deverá vincular-se ao mundo do trabalho e à prática social. Art. $3^{\circ} \mathrm{O}$ ensino será ministrado com base nos seguintes princípios: I - igualdade de condições para o acesso e permanência na escola; II - liberdade de aprender, ensinar, pesquisar e divulgar a cultura, o pensamento, a arte e o saber; III - pluralismo de ideias e de concepções pedagógicas; IV - respeito à liberdade e apreço à tolerância. (BRASIL, 2015, p. 09, grifos nossos).

A LDB afirma que o processo educativo abrange a formação dos indivíduos que se desenvolve nos movimentos sociais e nas manifestações culturais, além de vincular-se também à prática social, e ressalta que o ensino exige condições de igualdade para o acesso e a permanência dos estudantes na escola, além da liberdade de aprendizagem,

6. Disponível em: <http://reporteralagoas.com.br/novo/camara-de-maceio-adia-discussao-sobre-ideologiade-genero-na-educacao/>. Acesso em: 02 jan. 2016.

7. Disponível em: <http://g1.globo.com/sp/campinas-regiao/noticia/2015/11/camara-de-campinas-adiadebate-sobre-ideologia-de-genero.html>. Acesso em: 02 jan. 2016.

8. Disponível em: <http://www2.camara.leg.br/documentos-e-pesquisa/publicacoes/edicoes/paginasindividuais-dos-livros/lei-de-diretrizes-e-bases-da-educacao-nacional>. Acesso em: 27 jan. 2016. 
ensino, pesquisa e divulgação cultural, colaborando para o pluralismo de ideias e de concepções pedagógicas. Atualmente, a realidade da educação brasileira apresenta dados que contrariam as propostas apresentadas pela LDB, sobretudo com relação ao número de evasão de pessoas transgêneros e à violência contra alunos e alunas gays, lésbicas e bissexuais, como apontam os pesquisadores Borges e Meyer (2008), Dinis (2011) e Junqueira (2010). Dessa forma, uma das finalidades requeridas pela Lei de diretrizes e bases da educação básica não está sendo assegurada: nos referimos à formação para a cidadania e o desenvolvimento da tolerância recíproca em que se assenta a vida social, como descritos nos artigos abaixo:

Art. 22. A educação básica tem por finalidades desenvolver o educando, assegurar-lhe a formação comum indispensável para o exercício da cidadania e fornecer-lhe meios para progredir no trabalho e em estudos posteriores. (BRASIL, 2015, p. 17, grifos nossos)

Art. 32. IV - o fortalecimento dos vínculos de família, dos laços de solidariedade humana e de tolerância recíproca em que se assenta a vida social. (BRASIL, 2015, p. 23, grifos nossos).

O Brasil vem empreendendo esforços para efetivar mudanças no cenário de violência contra as mulheres e a população LGBTT nas escolas do País e modificar essa realidade, herança de uma colonialidade cultural. Para isso, conta, muitas vezes, com a promulgação de resoluções que possibilitem aos docentes o exercício de atividades e propostas pedagógicas desde a infância. A Resolução CNE/CP n. ${ }^{\circ}$ o1, de 15 de maio de 2016, prevê:

Art. $5^{\circ} \mathrm{O}$ egresso do curso de Pedagogia deverá estar apto a:

$\mathrm{X}$ - Demonstrar consciência da diversidade, respeitando as diferenças de natureza ambiental-ecológica, étnico-racial, de gêneros, faixas geracionais, classes sociais, religiões, necessidades especiais, escolhas sexuais, entre outras?.

Conforme a resolução emitida pelo Conselho Nacional de Educação, os estudantes egressos dos cursos de Pedagogia deverão, ao término da formação, não

9. Disponível em: <http://portal.mec.gov.br/cne/arquivos/pdf/rcpo1_o6.pdf>. Acesso em: 31 dez. 2015. 
apenas encontrar-se aptos para respeitar as diferenças de natureza de gênero, de faixas geracionais, raciais e sexuais, como também demonstrar consciência da diversidade. Alguns sinônimos do verbete demonstrar podem ser: exemplificar, exibir, expor, expressar, mostrar, provar e revelar, uma vez que o significado da palavra "demonstrar" é: "Fazer com que (alguma coisa) se torne evidente por meio de provas; fazer com que se torne conhecido; comprovar" ${ }^{{ }_{10}}$. Assim, cabe à pedagoga e ao pedagogo demonstrar, por meio da realização de conversas, projetos, atividades, entre outros recursos de caráter pedagógico, a pluralidade e a diversidade social brasileira, instruindo e orientando as crianças para que respeitem as diferenças de gênero.

As relações de gênero mencionadas aqui podem ser trabalhadas por meio do currículo oculto ${ }^{11}$, que é extremamente importante, uma vez que o currículo oficial é incapaz de prever as necessidades locais de cada escola e programar um conteúdo a ser desenvolvido especificamente para a realidade de cada unidade educacional.

Para José Gimeno Sacristán (1998, p. 43):

A acepção do currículo como conjunto de experiências planejadas é insuficiente, pois os efeitos produzidos nos alunos por um tratamento pedagógico ou currículo planejado e suas consequências são tão reais e efetivos quanto podem ser os efeitos provenientes das experiências vividas na realidade da escola sem tê-las planejado, às vezes nem sequer ser conscientes de sua existência. É o que se conhece como currículo oculto.

O currículo oculto aparece como um espaço significativo para que possamos, no dia a dia da sala de aula e da experiência com o cotidiano escolar e dos estudantes, elucidar alternativas temáticas, educativas e valorativas que respondam aos conflitos e anseios presentes na comunidade, os quais inevitavelmente atravessam os muros da escola.

Outro relevante respaldo encontra-se entre as concepções de proposta pedagógica inclusas nas Diretrizes Curriculares Nacionais para a Educação Infantil, publicadas pelo Ministério da Educação em $2010^{12}$, que determinam que as insti-

10. Disponível em: <http://www.dicio.com.br/demonstrar/>. Acesso em: 31 dez. 2015.

11. Conforme Silva (1999, p.78): "O currículo oculto é constituído por todos aqueles aspectos do ambiente escolar que, sem fazer parte do currículo oficial, explícito, contribuem, de forma implícita para aprendizagens sociais relevantes [...] o que se aprende no currículo oculto são fundamentalmente atitudes, comportamentos, valores e orientações".

12. Disponível em: $<$ http://portal.mec.gov.br/index.php?option=com_docman\&view=download\&alias=9769diretrizescurriculares-2012\&category_slug=janeiro-2012-pdf\&Itemid=30192>. Acesso em: 05 jan. 2016. 
tuições de educação infantil devem garantir o cumprimento pleno de sua função sociopolítica e pedagógica:

Construindo novas formas de sociabilidade e de subjetividade comprometidas com a ludicidade, a democracia, a sustentabilidade do planeta e com o rompimento de relações de dominação etária, socioeconômica, étnicoracial, de gênero, regional, linguística e religiosa. (BRASIL, 2010, p. 17).

Portanto, as contribuições do trabalho pedagógico são de suma importância para que as crianças desenvolvam reflexões e posturas éticas com relação às demandas políticas propostas pelas Diretrizes Curriculares Nacionais para a Educação Infantil, o que inclui necessariamente construir novas relações de sociabilidade e subjetividade a partir das perspectivas de gênero, consolidando as plataformas de acesso para a equidade e a valorização das atividades e dos papéis sociais de gênero na cultura brasileira.

Com relação ao Ensino Fundamental de nove anos, a Resolução n. 07 do Conselho Nacional de Educação, de 14 de dezembro de 2014, publicada pelo Diário Oficial da União e disponível on-line ${ }^{13}$ apresenta o seguinte artigo:

Art. 16 Os componentes curriculares e as áreas de conhecimento devem articular em seus conteúdos, a partir das possibilidades abertas pelos seus referenciais, a abordagem de temas abrangentes e contemporâneos que afetam a vida humana em escala global, regional e local, bem como na esfera individual. Temas como saúde, sexualidade e gênero, vida familiar e social, assim como os direitos das crianças e adolescentes, de acordo com o Estatuto da Criança e do Adolescente (Lei no 8.069/9o), preservação do meio ambiente, nos termos da política nacional de educação ambiental (Lei no 9.795/99), educação para o consumo, educação fiscal, trabalho, ciência e tecnologia, e diversidade cultural devem permear o desenvolvimento dos conteúdos da base nacional comum e da parte diversificada do currículo. $\$ 1^{\circ}$ Outras leis específicas que complementam a Lei no 9.394/96 determinam que sejam ainda incluídos temas relativos à condição e aos direitos dos idosos (Lei no $10.741 / 2003$ ) e à educação para o trânsito (Lei ${ }^{\circ}$ 9.503/97). $\mathbb{S} 2^{\circ} \mathrm{A}$ transversalidade constitui uma das maneiras de trabalhar os componentes curriculares, as áreas de conhecimento e os temas sociais em uma

13. Disponível em: <http://portal.mec.gov.br/dmdocuments/rceboo7_10.pdf >. Acesso em: 05 jan. 2016. 
perspectiva integrada, conforme as Diretrizes Curriculares Nacionais Gerais para a Educação Básica (Parecer CNE/CEB no 7/2010 e Resolução CNE/CEB no 4/2010). S $3^{\circ}$ Aos órgãos executivos dos sistemas de ensino compete a produção e a disseminação de materiais subsidiários ao trabalho docente, que contribuam para a eliminação de discriminações, racismo, sexismo, homofobia e outros preconceitos e que conduzam à adoção de comportamentos responsáveis e solidários em relação aos outros e ao meio ambiente. (BRASIL, 2010, seção 1, p. 34, grifos nossos).

O artigo 16 prevê que os conteúdos trabalhados abordem temas contemporâneos, os quais afetam a vida humana em escala global, regional, local e individual, e destaca como exemplos as questões de gênero e sexualidade. Visa, sobretudo, a partir de medidas educativas, colaborar para a eliminação de posturas e atitudes discriminatórias como o racismo, o sexismo, a homofobia e outros preconceitos. A legislação educacional vem há alguns anos produzindo seu arcabouço documental para priorizar e construir a escola como um espaço de interação, respeito e valorização das diferenças e da vida social e política entre alunos e alunas.

As menções do CNE para o Ensino Médio são semelhantes, adequando as propostas pedagógicas às séries e à idade dos estudantes. No inciso XV do Artigo $16,{ }^{14}$ destaca-se:

$\mathrm{XV}$ - valorização e promoção dos direitos humanos mediante temas relativos a gênero, identidade de gênero, raça e etnia, religião, orientação sexual, pessoas com deficiência, entre outros, bem como práticas que contribuam para a igualdade e para o enfrentamento de todas as formas de preconceito, discriminação e violência sob todas as formas (BRASIL, 2012, Seção 1, p. 20. grifo nosso).

Nesta resolução, a inclusão do termo “identidade de gênero" está diretamente relacionada ao tratamento de pessoas transgêneros, as quais não se identificam com o sexo biológico e com o papel de gênero socialmente prescrito para elas. Entretanto, cabe à escola e à comunidade promover, por meio do reconhecimento da identidade de gênero, a valorização e a garantia dos direitos humanos das pessoas

14. Disponível em: <http://pactoensinomedio.mec.gov.br/images/pdf/resolucao_ceb_002_30012012.pdf>. Acesso em: o5 jan. 2016. 
trans, respeitando o nome social, sua integridade física e seu acesso aos espaços a partir de sua relação de identificação.

No estado de São Paulo algumas leis já foram promulgadas, como a n.o 10.948, de 5 de novembro de 2001, que proíbe a discriminação por homofobia e transfobia e pune toda manifestação de violência praticada contra pessoas LGBT. Outro avanço foi o Decreto estadual n. 55.588, que dispõe sobre o tratamento nominal das pessoas transexuais e travestis nos órgãos públicos de São Paulo e dá providências correlatas.

Este decreto assegura às pessoas transexuais e travestis o direito à escolha de tratamento nominal nos atos e procedimentos promovidos no âmbito da Administração direta e indireta do Estado de São Paulo.

Mediante indicação da pessoa, seu nome social deverá constar em todos os documentos, fichas, formulários e crachás, e os servidores públicos deverão tratá-la pelo nome indicado. (SÃO PAULO, 2014, p. 29-30).

Além do arcabouço legal discorrido acima, a Constituição Federal's enfatiza, logo em seu primeiro título "Dos Princípios Fundamentais" (BRASIL, 1988/2015, p. 15): "A República Federativa do Brasil, formada pela união indissolúvel dos Estados e Municípios e do Distrito Federal, constitui-se em Estado Democrático de Direito e tem como fundamentos: [...] a dignidade da pessoa humana".

Seu artigo $3^{\circ}$ - IV diz que um dos objetivos fundamentais é "promover o bem de todos, sem preconceitos de origem, raça, sexo, cor, idade e quaisquer outras formas de discriminação" (1988/2015, p. 16). E o Artigo $5^{\circ}$ esclarece:

Todos são iguais perante a lei, sem distinção de qualquer natureza, garantindo-se aos brasileiros e aos estrangeiros residentes no País a inviolabilidade do direito à vida, à liberdade, à igualdade, à segurança e à propriedade, nos termos seguintes:

I- homens e mulheres são iguais em direitos e obrigações, nos termos desta Constituição; IV - é livre a manifestação do pensamento, sendo vedado o anonimato;

IX - é livre a expressão da atividade intelectual, artística, científica e de comunicação, independentemente de censura ou licença.

15. Disponível em: <http://www.imprensaoficial.com.br/PortalIO/download/pdf/Constituicoes_declaracao. pdf>. Acesso em: 27 jan. 2016. 
E referente à promoção da educação básica brasileira, descreve a Constituição Federal nos artigos 205 e 206 (BRASIL, 1988/2015, p. 130):

Art. 205. A educação, direito de todos e dever do Estado e da família, será promovida e incentivada com a colaboração da sociedade, visando ao pleno desenvolvimento da pessoa, seu preparo para o exercício da cidadania e sua qualificação para o trabalho.

Art. 206. O ensino será ministrado com base nos seguintes princípios:

II - liberdade de aprender, ensinar, pesquisar e divulgar o pensamento, a arte e o saber.

Como todos sabemos, a decisão legislativa de muitas câmaras dos municípios no Brasil extraiu, dos planos municipais de educação, a palavra "gênero", tornando-a invisível nos documentos oficiais, o que não significa se tratar de uma medida proibitiva que impeça docentes, coordenadores e direção de realizar atividades e projetos pedagógicos temáticos ou envolvendo as relações de gênero e sexualidade, pois qualquer ação ou medida de caráter proibitivo pode configurar inconstitucionalidade, uma vez que a Constituição da República Federativa do Brasil, as Leis de Diretrizes e Bases da Educação e as resoluções emitidas pelo Conselho Nacional de Educação fundamentam, priorizam e autorizam o trabalho pedagógico que valorize o respeito à pluralidade étnica, de gênero e sexual no País, garantindo a todos e todas a integridade dos direitos e o exercício pleno da cidadania.

Esta "onda conservadora" - e suas pautas políticas -, como ficou popularmente conhecida, é o reflexo histórico do processo de colonização do conhecimento e dos saberes, implicando diretamente na produção de discursos que constituem a subjetividade, como nos alerta Mignolo (2014).

Aníbal Quijano (2000, p. 342), sobre o processo de colonização, ressalta:

A colonialidade é um dos elementos constitutivos e específicos do padrão mundial de poder capitalista. Se funda na imposição de uma classificação racial/étnica da população do mundo como pedra angular do dito padrão de poder e opera em cada um dos planos, âmbitos e dimensões materiais e subjetivas, da existência social cotidiana e da escala social. Origina-se e mundializa-se a partir da América.

Para Quijano, como nos lembra Luciana Ballestrin (2013, p. 101), as categorias de raça, gênero e trabalho "foram as três linhas principais de classificação que constituíram a formação do capitalismo mundial colonial/ moderno no século XVI. 
É nessas três instâncias que as relações de exploração/dominação/conflito estão ordenadas".

O processo de descolonização do pensamento exige que sejamos capazes de aprender a desaprender, romper com categorias naturalizadas e inscritas no estatuto das verdades científicas ocidentais, que serviram, inclusive, como arma e caneta do poder colonial: a primeira como proposta de dizimação étnica e das resistências ao assujeitamento cultural empreendido desde o final do século XV e a segunda como ferramenta de inscrição simbólica e representativa da população na América, inaugurando sua entrada para o cenário da modernidade e do chamado mundo civilizatório.

\section{REFERÊNCIAS}

BALLESTRIN, Luciana. América Latina e o giro decolonial. Rev. Bras. Ciênc. Polit., Brasília, n. 11, p. 89-117, ago. 2013 .

BRASIL. Ministério da Educação. Secretaria de Educação Básica. Diretrizes curriculares nacionais para a educação infantil / Secretaria de Educação Básica. Brasília: MEC, SEB, 2010.

BRASIL. LDB nacional [recurso eletrônico]: Lei de diretrizes e bases da educação nacional: Lei no 9.394, de 20 de dezembro de 1996, que estabelece as diretrizes e bases da educação nacional. 11. ed. Brasília: Câmara dos Deputados, Edições Câmara, 2015. [Lei Darcy Ribeiro (1996)].

BRASIL; SÃO PAULO (Estado). Constituição da República Federativa do Brasil - 1988 (Atualizada até a Emenda Constitucional no 88, de 7 de maio de 2015) e Constituição do Estado de São Paulo (Atualizada até a Emenda Constitucional no 40, de 9 de abril de 2015). Reimpressão. São Paulo: Imprensa Oficial do Estado de São Paulo, 2015.

BORGES, Zulmira Newlands; MEYER, Dagmar Estermann. Limites e possibilidades de uma ação educativa na redução da vulnerabilidade à violência e à homofobia. Ensaio: Aval. Pol. Públ. Educ., Rio de Janeiro, v. 16, n. 58, p. 59-76, jan./mar. 2008.

BUTLER, Judith P. Problemas de gênero: feminismo e subversão da identidade. 2. ed. Rio de Janeiro: Civilização Brasileira, 2008.

CAMBI, Franco. História da Pedagogia. São Paulo: Editora Unesp, 1999.

CASTRO, Edgardo. Vocabulário de Foucault - um percurso pelos seus temas, conceitos e autores. Belo Horizonte: Autêntica, 2009.

DINIS, Nilson Fernandes. Homofobia e educação: quando a omissão também é signo de violência. Educar em Revista - UFPR, Curitiba, Brasil, n. 39, p. 39-50, jan./abr. 2011.

FOUCAULT, Michel. Vigiar e punir: nascimento da prisão. Petrópolis: Vozes, 1987.

JUNQUEIRA, Rogério Diniz. Currículo heteronormativo e cotidiano escolar homofóbico. Espaço do Currículo, v. 2, n. 2, p. 208-230, set./mar. 2010.

LANDER, Edgardo (Org.). A colonialidade do saber: eurocentrismo e ciências sociais. Perspectivas latino-americanas., Ciudad Autónoma de Buenos Aires, Argentina: CLACSO, set. 2005. (Colección Sur Sur). 
Bases e fundamentos legais para a discussão de gênero e sexualidade em sala de aula

MIGNOLO, Walter. Des-colonialidad del ser y del saber. (Videos indígenas y los limites coloniales de la izquierda) em Bolivia. 1. ed. - Buenos Aires: Del signo, 2006.

. Género y descolonialidad. Ciudad Autónoma de Buenos Aires: Del Signo, 2014.

MIGUEL, Luis Felipe; BIROLI, Flávia. Feminismo e política: uma introdução. 1. ed. - São Paulo: Boitempo, 2014.

QUIJANO, Aníbal. Colonialidad del poder y clasificación social. Journal of World-Systems Research, Pittsburgh, v. 11, n. 2, p. 342-386, 2000.

SACRISTÁN, José Gimeno. Currículo: uma reflexão sobre a prática. 3. ed. Tradução Ernani Ferreira da Fonseca Rosa. Porto Alegre: ArtMed, 1998.

SÃO PAULO (Estado). Secretaria da Justiça e da Defesa da Cidadania. Coordenação de Políticas Públicas para a Diversidade Sexual. Diversidade sexual e cidadania LGBT. São Paulo: SJDC/SP, 2014.

SILVA, Tomaz Tadeu da. Quem escondeu o currículo oculto. In: SILVA, Tomaz Tadeu da. Documento de identidade: uma introdução às teorias do currículo. Belo Horizonte: Autêntica, 1999.

\section{SOBRE OS AUTORES}

Alex Barreiro é Bacharel e Licenciado em História (Pontifícia Universidade Católica de Campinas), com especialização em História, Sociedade e Cultura (Pontifícia Universidade Católica de São Paulo). É Mestre e doutorando em Educação (Universidade Estadual de Campinas). Atualmente é docente nos cursos de História e Pedagogia das Faculdades Integradas Maria Imaculada - e professor da rede pública municipal de Mogi Guaçu/SP.

E-mail: barreiroalex86@gmail.com

Fernando Henrique Martins é Graduado em História (Pontifícia Universidade Católica de Campinas), com Especialização em História Social (Faculdades Integradas Maria Imaculada).

E-mail:1hemao@yahoo.com.br

Recebido em 21 de março de 2016 e aprovado em 15 de dezembro de 2016. 